\title{
Novel observations of capelin (Mallotus villosus) spawning directly on a brown algae species (Desmarestia viridis) in coastal Newfoundland, Canada
}

\author{
Laura M. Bliss ${ }^{* 1}$ and Gail K. Davoren ${ }^{1}$ \\ ${ }^{1}$ University of Manitoba, Department of Biological Sciences, Winnipeg, Manitoba R3T 2N2 \\ *Corresponding Author: Laura M. Bliss, blissl@myumanitoba.ca
}

Bliss, L.M., and Davoren, G.K. 2021. Novel observations of capelin (Mallotus villosus) spawning directly on a brown algae species (Desmarestia viridis) in coastal Newfoundland, Canada. J. Northw. Atl. Fish. Sci., 52: 29-37. https://doi.org/10.2960/J.v52.m734

Funding Information

This project was supported partially by a financial contribution from Fisheries and Oceans Canada, through the Coastal Environmental Baseline Program, for research in Placentia Bay, Newfoundland, Canada during 2018-2020. Additional funding was provided by a University of Manitoba Graduate Fellowship to L.M.B.

\begin{abstract}
Capelin (Mallotus villosus) is a key forage fish species within its circumpolar range. This species' importance lies in its role in the typical marine 'wasp-waist' food web, where capelin acts as a conduit for energy flow from lower to higher trophic levels. Herein we describe a novel observation of capelin spawning subtidally on an annual brown algae species, Desmarestia viridis, during July-August 2019 in Placentia Bay, Newfoundland, Canada. Based on extensive video surveys of the seabed along with shoreline surveys and sediment sampling, we did not find other nearby sites with typical capelin subtidal and intertidal spawning habitat (i.e. medium sand to pebble gravel). Findings suggest that capelin spawned directly on this brown algae species, D. viridis. Eggs adhered to D. viridis developed normally and hatched successfully. As temperatures of intertidal areas are predicted to increase above temperatures suitable for capelin egg rearing $\left(2-12^{\circ} \mathrm{C}\right)$ with climate change, $D$. viridis may become a high-quality subtidal spawning habitat for capelin and other fish species. In support, this algal species is adapted to colonize high disturbance areas, allowing protection from egg predators in a high flow environment while also being resistant to urchin grazing.
\end{abstract}

Keywords: Capelin; spawning habitat; Mallotus villosus; Northwest Atlantic; Newfoundland; Desmarestia viridis

\section{Introduction}

Capelin Mallotus villosus (Müller, 1776) is an important forage fish species both commercially and ecologically in many northern marine ecosystems, whereby it plays a key role in funnelling energy from lower to higher trophic levels (Lavigne, 1996; Carscadden and Vilhjalmsson, 2002). In the Northwest Atlantic, the capelin population on the Newfoundland shelf collapsed in 1991 (Buren et al., 2014) and has yet to recover (Buren et al., 2014, 2019). The lack of recovery is thought to be related to bottom up processes, whereby changing seasonal sea ice dynamics and timing of spawning limit recruitment due to mismatches between larval emergence and favourable environmental conditions (i.e. low predator and high prey densities) for larval survival (Buren et al., 2014; Mullowney et al., 2016; Murphy et al., 2018; Lewis et al., 2019). Although the primary reproductive mode in coastal Newfoundland is thought to be intertidal ('beach') spawning (Nakashima and Wheeler, 2002), there are also historical reports of widespread and consistent subtidal spawning (Templeman 1948), which are further supported by more recent studies (Nakashima and Wheeler, 2002; Davoren et al., 2006). As capelin eggs become sticky after fertilization (Davenport et al., 1986), the spawning site becomes the egg-rearing site. Although larvae hatch in good condition from some subtidal sites (Penton and Davoren, 2008) but not others (Nakashima and Wheeler, 2002), incubation is often longer in subtidal habitat compared to beach habitat due to cooler water temperatures (Penton et al., 2012), resulting in longer exposure to egg predators (Frank and Leggett, 1984), less growth/development time prior to winter, and potentially a higher probability of temporal mismatches with favorable environmental conditions. Overall, little 
information exists regarding the contribution of subtidal habitat to capelin recruitment (Davoren et al., 2007).

Similar to intertidal spawning habitat, studies have linked subtidal capelin spawning locations primarily with a sediment size range (0.5-25mm; Templeman, 1948; Nakashima and Wheeler, 2002; Davoren et al., 2007; Penton and Davoren, 2012, 2013) and secondarily with a temperature range $\left(2-12^{\circ} \mathrm{C}\right.$; Carscadden et al., 1989; Davoren, 2013; Crook et al., 2017), with highest hatching success between $4-7^{\circ} \mathrm{C}$ (Penton and Davoren, 2013). For subtidal spawning, bathymetric features such as depressions (i.e., trenches or 'holes') are also important, as they retain suitable spawning sediment in specific areas (Penton and Davoren, 2012). This sediment size range is key for proper oxygenation and waste removal (Penton et al., 2012) and temperature range is vital to reduce the rate of abnormal egg development (Shadrin et al., 2020). As fertilized capelin eggs adhere to all nearby structures, eggs have been anecdotally observed and reported adhered to algae by local fishers, along with other structures (e.g., traps, trawls, other fishing nets and anchors) from 5-45m depth (Templemen, 1948). Adherence to algae and these other structures, however, is thought to occur incidentally, whereby eggs drift from nearby sediment-based spawning sites.
Here we describe a novel observation of capelin spawning subtidally on brown algae, Desmarestia viridis, during July-August 2019 (Fig. 1) in Placentia Bay, Newfoundland, Canada. D. viridis is a canopy-forming, annual brown algal species that is usually found in nearshore intertidal and subtidal areas $(<12 \mathrm{~m})$ at higher latitudes, most often in Arctic or sub-Arctic regions (van Oppen et al., 1993). We investigated whether capelin spawned directly on $D$. viridis or whether the capelin eggs adhered to this algal species incidentally. These observations were made while investigating the spatial extent of subtidal spawning of capelin within this Newfoundland bay.

\section{Materials and Methods}

Underwater camera surveys were conducted during July-August, 2019 on the east coast of Placentia Bay, Newfoundland, Canada (Fig. 2A) within 12 areas highlighted as being potentially important for subtidal capelin spawning during fisher interviews adapted from Sjare et al. (2003). To determine camera survey sites, a $4.6 \mathrm{~km}$ by $2.3 \mathrm{~km}$ rectangle was drawn around the center of each of the 12 potential subtidal spawning areas identified by interviewees. Within each of these 12 rectangles, we used ArcMap 10.3.1 to generate 10 random sites at least $500 \mathrm{~m}$ apart, which was based on the size of the chartered fishing
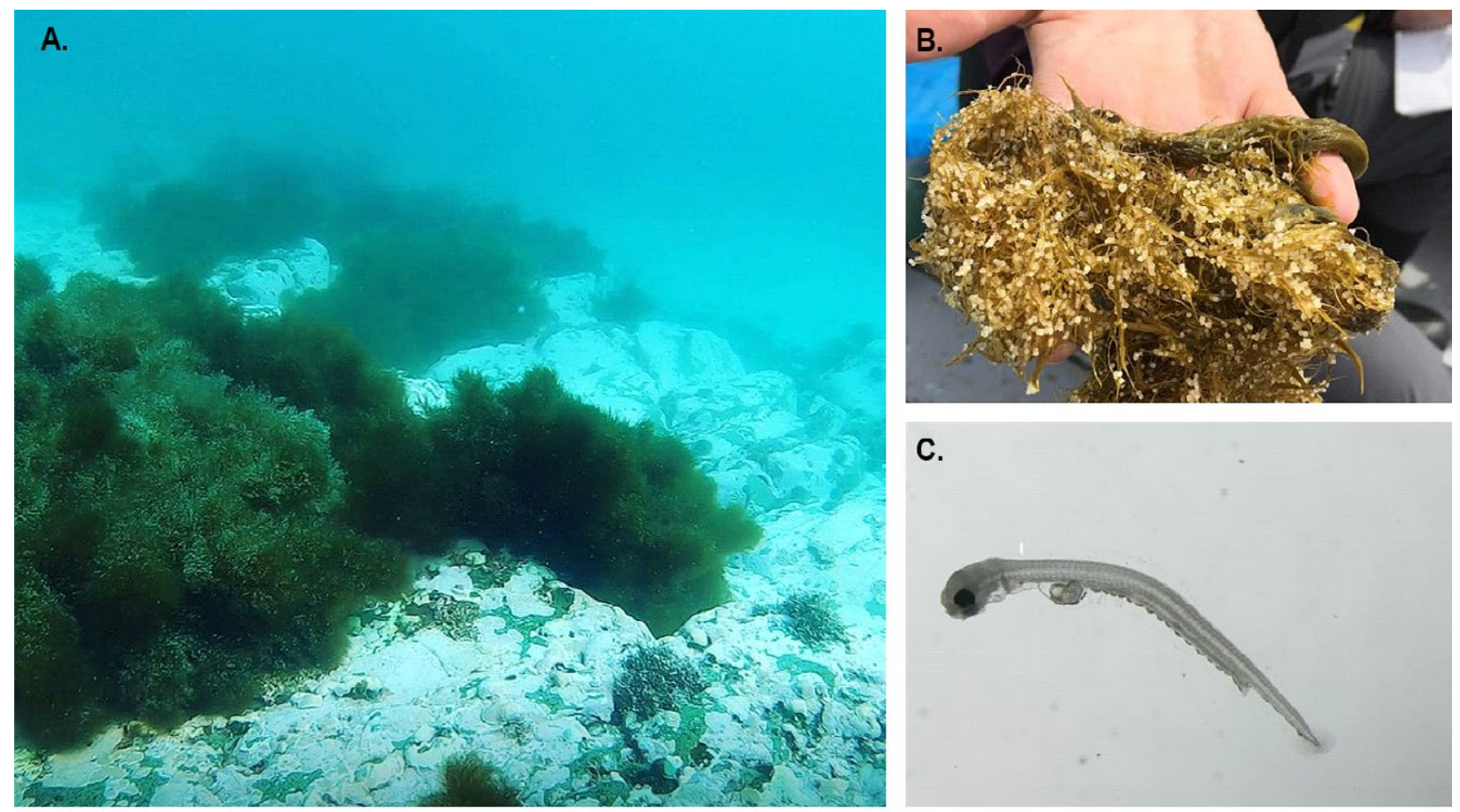

Fig. 1. Screenshot from camera surveys conducted on 20 July 2019 showing Desmarestia viridis covered in adherent capelin (Mallotus villosus) eggs (A). Photograph of a sample of D. viridis covered in yellow capelin eggs collected on 20 July 2019 (B). A microscope (Olympus SZX7, 25X magnification) photograph of the capelin larvae that hatched from laboratory-raised eggs found on $D$. viridis $(\mathbf{C})$. 
BLISS and DAVOREN: Observations of capelin spawning directly on a brown algae species in coastal Newfoundland, Canada 31
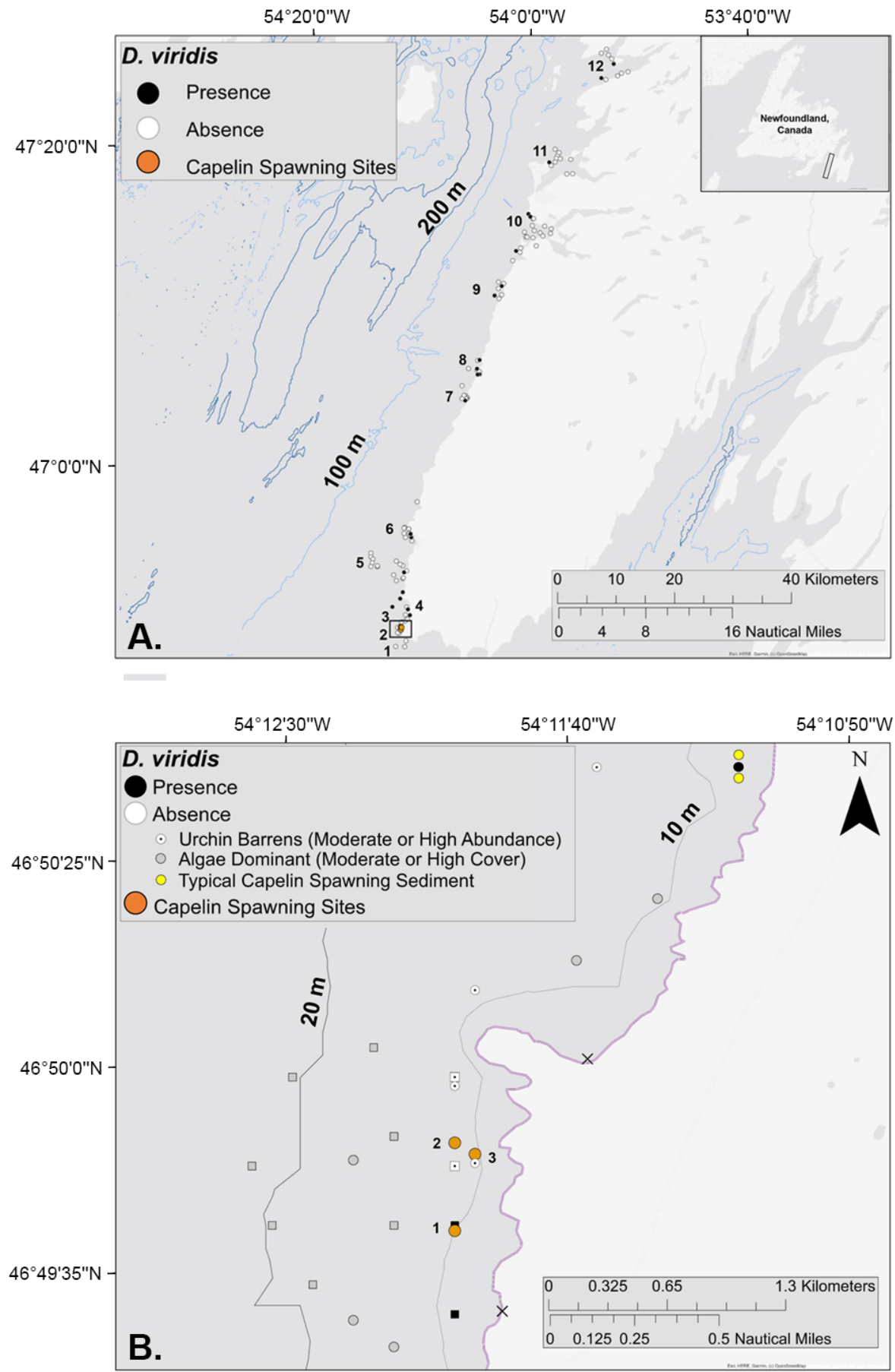

Fig. 2. The location of the east coast of Placentia Bay, Newfoundland, Canada (A, inset). (A) The distribution of Desmarestia viridis along the east coast of Placentia Bay based on the 136 sites surveyed during July-August, 2019 within the 12 areas highlighted as being potentially important for subtidal capelin (Mallotus villosus) spawning during fisher interviews. The sites where capelin eggs were adhered to $D$. viridis are indicated (capelin spawning sites) and the square indicates the region highlighted in $\mathbf{B}$. (B) The fine-scale distribution of $D$. viridis with adherent capelin eggs (capelin spawning sites 1-3) and without capelin eggs, along with nearby sites that were both absent of $D$. viridis and one of the following: algal-dominated, urchin barrens, or typical capelin subtidal spawning sediment (medium sand to pebble gravel). Squares represent the 11 delineation sites, while circles represent the original randomly generated sites. The purple line along the coast indicates the area searched with binoculars for typical capelin intertidal spawning habitat and evidence of intertidal spawning, while the black Xs indicate beaches, which were comprised of large cobbles and boulders. 
vessel $(6 \mathrm{~m})$ and expected drift, to reduce the probability of covering the same area in separate surveys. In addition to these 120 random sites, other sites were added based on the previous fishing experience and knowledge of chartered fishers in the area, for a total of 136 sampling sites.

Prior to beginning camera surveys, we regularly contacted local fishers and monitored a citizen-science social media platform (www.ecapelin.ca) to ensure that boat-based surveys began after capelin had arrived in coastal regions and had begun spawning in the bay. We sequentially visited each site, during which we deployed a metal frame (meshless crab or lobster pot) with two underwater video cameras (GoPro Hero 7) attached along with a data logger (Star-Oddi DST) that measured temperature $\left({ }^{\circ} \mathrm{C}\right)$ and salinity via conductivity $(\mathrm{mS} / \mathrm{cm})$ every $5 \mathrm{~s}$. The metal frame was lowered to the seabed where it remained for 5 min to allow instrumentation to calibrate, and then was lifted $\sim 1 \mathrm{~m}$ off the seabed and allowed to drift for $4 \mathrm{~min}$ on average ( $\pm 6 \mathrm{~s}$ ), or $\sim 250-300 \mathrm{~m}$, to explore more of the seabed immediately adjacent to each site for the presence of capelin eggs.

After the camera surveys were completed at each site, mean depth, temperature and salinity were derived from the data logger. Videos for each survey site were analyzed to determine the dominant sediment type, occurrence of capelin eggs, along with a qualitative index (i.e., high, moderate, low, and zero) of the percent cover of $D$. viridis and other algal species, and abundance of green urchins (Strongylocentrotus droebachiensis). For this paper, we focus on $D$. viridis because this was the only algal species on which adherent capelin eggs were found. We used the Wentworth Scale to qualitatively classify the dominant granulated sediment type on videos (Wentworth, 1922).

To determine if capelin eggs were present, sediment was sampled using a $15-\mathrm{cm}^{2}$ Ponar Grab system. Capelin eggs adhered to algae were also incidentally sampled when algae became tangled in our metal frame. Eggs were preserved in Stockard's $(50 \mathrm{~mL}$ formaldehyde, $37 \%$ solution; $40 \mathrm{~mL}$ glacial acetic acid; $60 \mathrm{~mL}$ glycerin; $850 \mathrm{~mL}$ sea water) and later examined under a dissecting microscope (Olympus SZX7) to determine species identity based on egg size and colour (Fridgeirsson, 1976), as well as comparison to reference capelin egg samples collected from active capelin spawning sites in other areas of Newfoundland. We also quantified the percentage of eggs in different developmental stages within at least one random sample of 50-100 eggs from each site. Following Frank and Leggett (1981), early developmental stages (Stages I-II) represented recent spawning, while later developmental stages (Stages III-VI) represented stages closer to hatching. Eggs adhered to algae were also lab- reared within a controlled environmental chamber at $\sim 8^{\circ} \mathrm{C}$ until hatch to confirm species identity using morphological characteristics (Fahay, 2007).

\section{Ethical Statement}

The care and use of experimental animals complied with Canadian Council of Animal Care animal welfare laws, guidelines and policies as approved by Canadian Council of Animal Care (Protocol: F16-017/1/2/3).

\section{Results}

During July-August 2019, we completed camera surveys at 136 unique sites within 12 potential subtidal capelin spawning areas in eastern Placentia Bay to determine the occurrence of capelin eggs (sampling dates: 16, 20, 21, 23, 25, 27 July and 6, 7, 9, 15 August). On 20 July 2019, we discovered eggs adhered to $D$. viridis during camera surveys at three sites within $128-483 \mathrm{~m}$ of each other in one of the 12 potential areas (Fig. 2B). The seabed substrate was characterized as bedrock with no granulation at all three sites (Fig. 1A). While drifting away from each site, we did not find more typical capelin spawning sediment or capelin eggs adhered to any structures immediately adjacent to each site. We collected eggs from two of the three sites on the day of discovery (20 July), which were lab-raised to hatch and later identified as capelin larvae (Fig. 1B, 1C). Initial egg samples revealed 57\% of capelin eggs at site 1 were in earlier stages of development (Stages I-II), while a lower percentage $(17 \%)$ were in early stages at site 2 (Table 1). These three sites were revisited on August 1, 10 and 11, 2019. On 1 August, we only sampled eggs to monitor development (no camera surveys), but were unable to obtain a sample from sites 2 and 3 due to high tidal activity. Eggs sampled at site 1 on 1 August were all in later stages (III-VI), indicating no recent spawning. Note that abnormally developing, empty or dead eggs were not found in any sample. On 10 and/or 11 August, capelin eggs were no longer found adhered to algae at any of the three sites and the percent cover of $D$. viridis was lower relative to 20 July (Table 1 ). Temperature-based incubation duration was estimated for each site to be 16-21 d from 20 July, based on the equation in Frank and Leggett (1981), suggesting that the eggs had likely hatched by 10/11 August.

To determine if there was a nearby beach spawning site, we thoroughly surveyed the coastline from the boat ( $\sim 500 \mathrm{~m}$ offshore) using binoculars (purple line; Fig. $2 \mathrm{~B}$ ) within $\sim 5 \mathrm{~km}$ north and south of the three spawning sites during work at or nearby these sites (20-21, 23 July; 1, $10-11$ August). The general topography of the coastline was $120 \mathrm{~m}$ cliffs, with two $2 \mathrm{~m}$ wide beach sites. However, 

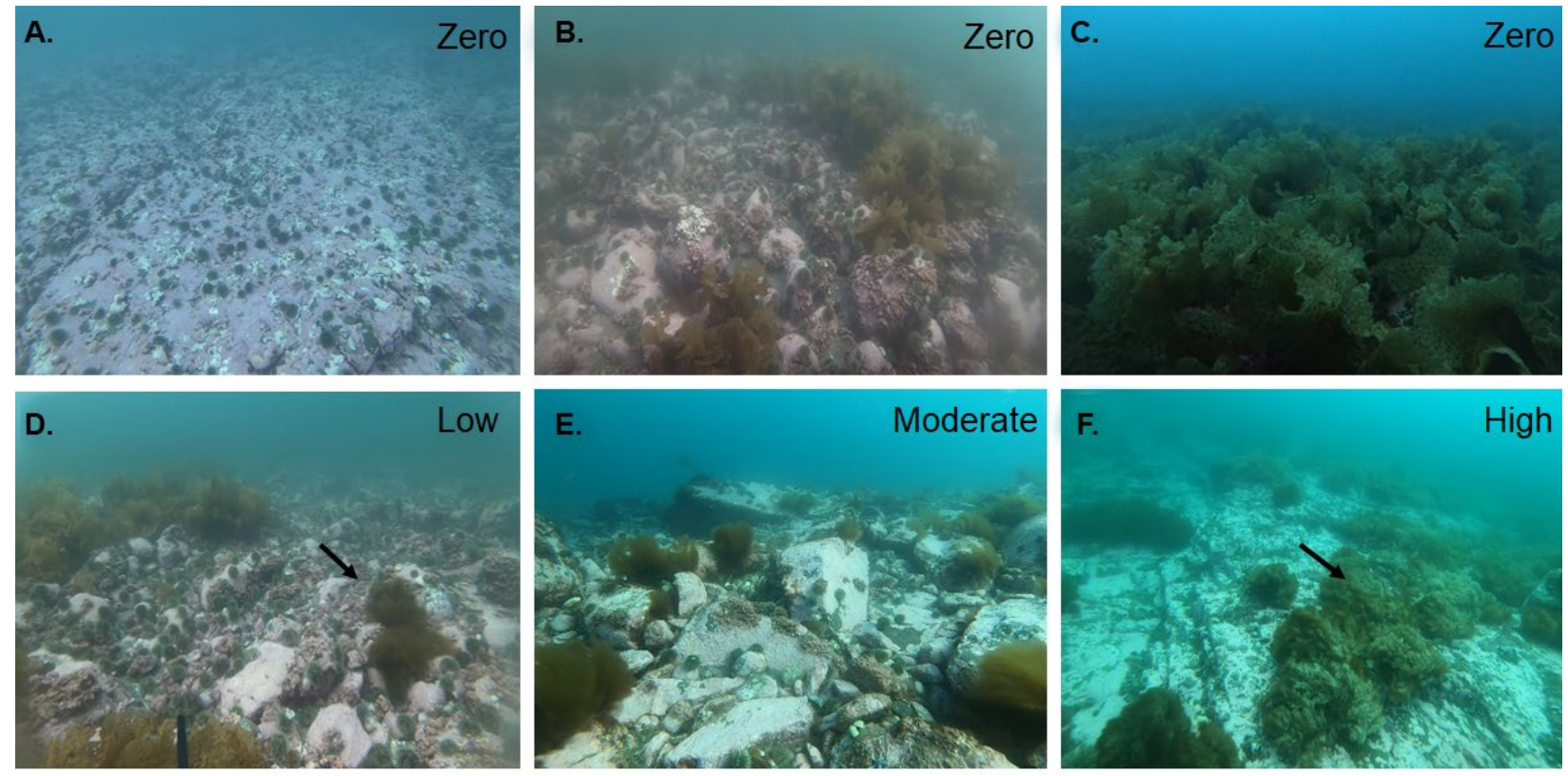

Fig. 3. Photographs from underwater video (GoPro Hero 7) during surveys for capelin (Mallotus villosus) subtidal spawning habitat in July-August, 2019 in Placentia Bay, Newfoundland, Canada. Examples of sites where D. viridis was absent (A-C) are shown, including low algal cover and a high density of green urchins Strongylocentrotus droebachiensis (A), moderate cover of Agarum clathratum (B), and high cover of A. clathratum (C). Examples of low, moderate, and high density of $D$. viridis (D-F) are also shown, including $A$. clathratum present with low $D$. viridis cover (D). Note the arrows indicate $D$. viridis $(\mathbf{D})$ and yellow capelin eggs adhered to $D$. viridis $(\mathbf{F})$.

these beaches were composed mostly of larger cobble and boulders fallen from the cliffside. The next nearest site with typical capelin subtidal spawning sediment $(0.5-25 \mathrm{~mm})$ was $2.5 \mathrm{~km}$ north of our sites (Fig. 2B, yellow circles), but eggs were not found adhered to the sediment when sampled on 21 and 23 July.

To determine if there was a subtidal spawning bed with more typical capelin spawning sediment size ranges from which fertilized eggs may have incidentally drifted to our three subtidal spawning sites, we conducted additional camera surveys on 10 August. To do this, we generated 11 more camera survey sites ('delineation sites') in a diamond-like shape around our three capelin spawning sites. Delineation sites were spaced $\sim 500 \mathrm{~m}$ apart to cover as much of the un-surveyed area near the three spawning sites while minimizing repeatedly covering the same areas (Fig. 2B, squares). Based on video analysis, all delineation sites were identified as bedrock with no granulation and $D$. viridis was only present at two of the shallowest sites $(8-10 \mathrm{~m}$; Fig. 2B). The remaining nine delineation sites had either high densities of green urchins and very little to no algal species ( $n=2$ sites; Fig. $3 \mathrm{~A})$ or high percent cover of other algal species $(n=7$ sites; Fig. 3B, $3 c)$. Capelin eggs were not found adhered to $D$. viridis, other algal species or bedrock at or nearby any of the 11 delineation sites.
We revisited these sites during 2020 and 2021 to determine if $D$. viridis remained present and capelin eggs were consistently adhered. On 5 August 2020, we conducted camera surveys at all three spawning sites from 2019 and all 11 delineation sites. At the three sites where capelin eggs had been found adhered to $D$. viridis, capelin eggs were not present and $D$. viridis was absent at sites 1 and 2 (Table 1); however, D. viridis was present $100 \mathrm{~m}$ inshore from the original location of site 1 . Site 3 was the only site with $D$. viridis present but no capelin eggs were found. Of the 11 delineation sites, $D$. viridis was present again at the same two inshore sites $(8-9 \mathrm{~m})$ from 2019, and the remaining nine sites continued to be characterized as bedrock with no granulation with either high densities of green urchins and little to no algal cover ( $n=2$ sites; Fig. $3 \mathrm{~A}$ ) or high percent cover of other algal species ( $n=7$ sites; Fig. 3B, 3C). During 2021, we revisited the three spawning sites from 2019 on 12-15 July and $D$. viridis was found with capelin eggs adhered on 15 July nearby site 1 .

\section{Discussion}

During July 2019, we documented capelin spawning on the algal species $D$. viridis. After systemically surveying adjacent and nearby subtidal areas as well as intertidal areas along the coast (Fig. 2B), we were unable to find 
Table 1. Depth, temperature, salinity and percent cover of Desmarestia viridis (i.e. high, moderate, low, zero) at each of the three sites at which capelin eggs were found adhered to D. viridis during July and August 2019, which were resurveyed during August 2020. Samples of capelin eggs were obtained on 20 July 2019 during underwater camera surveys and egg sampling was also attempted on 1 August 2019 without camera surveys. The percentage of eggs in early developmental stages (Stages I-II) and later stages (Stages III-VI) are indicated for each sample. All capelin eggs were absent by 10 and 11 August 2019 during camera surveys.

\begin{tabular}{|c|c|c|c|c|c|c|c|c|}
\hline $\begin{array}{c}\text { Sites with } \\
\text { capelin eggs }\end{array}$ & Date & $\begin{array}{l}\text { D. viridis } \\
\text { cover }\end{array}$ & $\begin{array}{l}\text { Depth } \\
(\mathrm{m})\end{array}$ & $\begin{array}{c}\text { Bottom } \\
\text { Temperature }\left({ }^{\circ} \mathrm{C}\right)\end{array}$ & $\begin{array}{l}\text { Salinity } \\
(\mathrm{mS} / \mathrm{cm})\end{array}$ & $\begin{array}{c}\text { Eggs } \\
\text { Present? }\end{array}$ & $\begin{array}{l}\text { Stages I-II } \\
(\%)\end{array}$ & $\begin{array}{c}\text { Stages III-VI } \\
(\%)\end{array}$ \\
\hline \multirow{5}{*}{$\begin{array}{c}\text { Site } 1 \\
{\left[46.828^{\circ} \mathrm{N}\right.} \\
\left.54.200^{\circ} \mathrm{W}\right]\end{array}$} & $20 \mathrm{Jul} 2019$ & High & 10 & 4.3 & 43.7 & Yes & 57 & 43 \\
\hline & 1 Aug 2019 & - & - & - & - & Yes & 0 & 100 \\
\hline & 10 Aug 2019 & Low & 10 & 7.6 & 46.4 & No & - & - \\
\hline & 11 Aug 2019 & Moderate & 10 & 10.9 & 49.2 & No & - & - \\
\hline & 5 Aug 2020 & Zero & 11 & 11.3 & 46.3 & No & - & - \\
\hline \multirow{4}{*}{$\begin{array}{c}\text { Site } 2 \\
{\left[46.831^{\circ} \mathrm{N},\right.} \\
\left.54.199^{\circ} \mathrm{W}\right]\end{array}$} & 20 Jul 2019 & Low & 10 & 4.6 & 44.0 & Yes & 17 & 83 \\
\hline & 1 Aug 2019 & - & - & - & - & No & - & - \\
\hline & 10 Aug 2019 & Zero & 12 & 7.4 & 46.0 & No & - & - \\
\hline & 5 Aug 2020 & Zero & 14 & 9.7 & 44.4 & No & - & - \\
\hline \multirow{3}{*}{$\begin{array}{c}\text { Site } 3 \\
{\left[46.830^{\circ} \mathrm{N},\right.} \\
\left.54.199^{\circ} \mathrm{W}\right]\end{array}$} & $20 \mathrm{Jul} 2019$ & Moderate & 9 & 4.7 & 43.7 & Yes & - & - \\
\hline & 11 Aug 2019 & Zero & 10 & 8.1 & 46.6 & No & - & - \\
\hline & 5 Aug 2020 & Low & 11 & 8.2 & 43.7 & No & - & - \\
\hline
\end{tabular}

subtidal or intertidal capelin spawning sites on typical sediment (i.e. medium sand to pebble gravel; Nakashima and Wheeler, 2002; Penton and Davoren, 2012). Although we cannot rule out that capelin spawned on small patches of undetected intertidal or subtidal sediment nearby our three algal capelin spawning sites, it is unlikely that eggs drifted from these sites and adhered only to $D$. viridis in the high densities observed despite the concurrent presence of other algal species. Overall, this evidence suggests that capelin spawned directly on $D$. viridis.

As the capelin eggs likely hatched successfully from D. viridis in the field, this algal species may represent a favourable capelin spawning habitat. Indeed, $D$. viridis may provide protection for developing eggs from predators, by providing a refuge for eggs away from benthic-feeding predators, such as flounder (Frank and Leggett, 1984), crabs (Mikkelsen and Pedersen, 2017), and amphipods (DeBlois and Leggett, 1993). Additionally, the sweeping motion of the algal branches deters urchin predation, allowing $D$. viridis to form high-density algal beds in regions with high wave action (Konar, 2000; Gagnon et al., 2006) and providing further protection from pelagic fish egg predators (Gagnon et al., 2006; Blain, 2013). Therefore, depositing eggs on $D$. viridis in areas of high wave action may provide a fixed incubation habitat with low predation for capelin eggs. The sweeping motion also likely results in regular oxygen replenishment and waste removal from the water surrounding eggs. Although the high acidity $\left(\mathrm{H}_{2} \mathrm{SO}_{4}\right)$ of $D$. viridis might be considered an unsuitable, or even detrimental, incubation habitat for capelin eggs, sulphuric acid is only released at senescence, which is initiated $>12^{\circ} \mathrm{C}$ (Blain and Gagnon, 2013; Gagnon et al., 2013). Indeed, although $D$. viridis can survive short periods of average ocean temperatures up to $23^{\circ} \mathrm{C}$ (Breeman, 1988), it undergoes a rapid die-off when average temperatures are $>12^{\circ} \mathrm{C}$ for extended periods (e.g. 1 month; Gagnon et al., 2013) and reproduction is inhibited at $10^{\circ} \mathrm{C}$ (Breeman, 1988). The higher temperatures during $2020\left(8.2-11.3^{\circ} \mathrm{C}\right.$; Table 1$)$, therefore, 
might explain the lower presence and density of $D$. viridis at the same inshore sites relative to 2019. Overall, if the conditions are favorable (i.e. high wave action and $\leq 12^{\circ} \mathrm{C}$ ), $D$. viridis may be a high-quality incubation habitat for capelin eggs. In support, we found many sites with high algal cover in our study area, but never found capelin eggs attached to algal species other than $D$. viridis. Previous studies also reported that $D$. viridis is a preferred algal species for fish egg deposition in coastal Newfoundland relative to other algal species (e.g., Desmarestia aculeata, Agarum clathratum; Blain, 2013).

As $D$. viridis is resistant to urchin predation in areas of high wave action, it is highly successful at colonizing these areas (Konar, 2000; Gagnon et al., 2006). This might explain the high densities of D. viridis observed (Fig. 3D-F) in inshore, shallow areas (2019: $10 \pm 4 \mathrm{~m}$; 2020: $13 \pm 4 \mathrm{~m}$ ), which are known to be high disturbance areas due to wave action. Other nearby sites, however, also had high densities of green urchins (Fig. 3A), which matched the description of green urchin barrens, previously defined as areas where algae is absent with high sea urchin densities (Konar, 2000). Previous studies in coastal Newfoundland have identified $D$. viridis as a first successional stage in the recolonization of urchin barrens, allowing the colonization of other algal species, such as the perennial Agarum cribrosum (e.g., Fig. 3B, 3C, and 3D) and Alaria esculenta (Gagnon et al., 2003; Molis et al., 2009). This might explain the deeper sites farther offshore being dominated by these other algal species (Fig. 3B-C) in our study area. As algal beds are important for a variety of ecosystem functions (e.g., fixed carbon source/primary productivity, habitat/shelter), shifts from algal-dominated to urchin-dominated alternative stable states (Folke et al., 2004; Stewart and Konar, 2012; FilbeeDexter and Scheibling, 2014) can be considered a collapse of the algal bed ecosystem (Chapman, 1981; Chapman and Johnson, 1990; Filbee-Dexter and Scheibling, 2014; Graham, 2004). Indeed, the lack of algal beds results in the reduction in fixed carbon and shelter availability which cascades up the food web negatively affecting higher trophic levels (Gaines and Roughgarden, 1987; Duggins et al., 1989).

Although capelin eggs were only found adhered to D. viridis at three of the 25 sites this algal species was observed during 2019, citizen science reports of capelin beach spawning (www.ecapelin.ca) suggested that capelin likely did not move further north of our three spawning sites into Placentia Bay during this year. Additionally, although capelin eggs were only found adhered to $D$. viridis at these three sites during two out of three years, citizen science reports (www.ecapelin.ca) suggested lower spawning capelin biomass during the year when capelin spawn was not found adhered to this algal species (2020) relative to the two years when capelin eggs were found adhered $(2019,2021)$. These observations suggest that $D$. viridis may be used as an alternate subtidal spawning habitat when spawning capelin and this algal species co-occur and are both at least moderately abundant. The extent and consistency $D$. viridis is used as a spawning habitat by capelin is an important avenue for future research.

The high overlap between favourable habitat characteristics of incubating capelin eggs and $D$. viridis in coastal Newfoundland, including temperature $\left(2-12^{\circ} \mathrm{C}\right.$; Penton and Davoren, 2012; Davoren, 2013; Crook et al., 2017) and depth (<40m; Penton and Davoren, 2012), suggest that the distribution of subtidal capelin spawning sites and that of $D$. viridis are similar. Current climate change models for Newfoundland predict that by 2063 bottom temperature will increase up to $0.4-2.1^{\circ} \mathrm{C}$ along the coast (Loder et al., 2013). Although capelin may be more likely to shift their range in response to this predicted change in ocean climate over the long-term (Rose, 2005), short-term responses may be habitat shifts within their current range. With continued increases in temperature and temperature variability at intertidal capelin spawning sites, capelin may initially occupy cooler subtidal habitat more relative to warm, beach spawning habitat to ensure offspring survival (Nakashima and Wheeler, 2002; Davoren, 2013; Penton and Davoren, 2013; Crook et al., 2017). If spawning habitat is limited, as suggested by ongoing beach spawning habitat restoration work, this shift may lead to lower availability of favourable spawning habitat resulting in a recruitment bottleneck. The widespread distribution of $D$. viridis in nearshore regions ( 25 out of 136 sites; Fig. 2A), however, may reduce the chances of a climate change-induced bottleneck if subtidal beds of $D$. viridis are commonly used as spawning habitat by capelin. Alternately, as $D$. viridis is an annual species and is sensitive to variation in temperature (Blain and Gagnon, 2013; Gagnon et al., 2013), the occurrence of this algal species may also decrease within their current range in the future. Nonetheless, as $D$. viridis is resistant to urchin grazing in areas with high wave action, this species may be able to colonize newly or highly disturbed areas with suitable temperature, thereby dynamically establishing favourable annual subtidal spawning habitat for capelin.

\section{Acknowledgements}

This project was supported partially by a financial contribution from Fisheries and Oceans Canada, through the Coastal Environmental Baseline Program, for research in Placentia Bay, Newfoundland, Canada during 2018-2020. Additional funding was provided by a University of Mani- 
toba Graduate Fellowship to L.M.B. We are indebted to the local captains in Newfoundland P.L. and A.E. for their assistance with fieldwork. Thanks to the following people: N. Dawes, J. Marsh, S. Morrison, and K. d'Entremont for assistance with field work; J. Zamon for feedback on initial drafts; and two anonymous reviewers for insightful comments on earlier drafts of this manuscript.

\section{Contributions}

L.M.B. was responsible for data generation, survey design, project design, data analysis, fieldwork, and manuscript preparation. Further, L.M.B acquired additional funding from the University of Manitoba.

G.K.D. contributed to project design, acquired the majority of the funding from Fisheries and Oceans Canada through the Coastal Environmental Baseline Program, provided edits and feedback on the project as it developed and established the original idea for the project.

\section{References}

Blain, C., and Gagnon, P. 2013. Interactions between thermal and wave environments mediate intracellular acidity $\left(\mathrm{H}_{2} \mathrm{SO}_{4}\right)$, growth, and mortality in the annual brown seaweed Desmarestia viridis. Journal of Experimental Marine Biology and Ecology, 440: 176-184. https://doi. org/10.1016/j.jembe.2012.12.013

Blain, C. O. 2013. Acid $\left(\mathrm{H}_{2} \mathrm{SO}_{4}\right)$ production, persistence, and functional importance of the annual, brown seaweed Desmarestia viridis in Newfoundland, Canada (Masters thesis, Memorial University, Canada). Available from Memorial University Library https://research.library.mun. $\underline{\mathrm{ca} / 11687 /}$.

Breeman, A. M. 1988. Relative importance of temperature and other factors in determining geographic boundaries of seaweeds: Experimental and phenological evidence. Helgoländer Meeresuntersuchungen, 42: 199-241. https:// doi.org/10.1007/BF02366043

Buren, A. D., Koen-Alonso, M., Pepin, P., Mowbray, F., Nakashima, B., Stenson, G., Ollerhead, N., and Montevecchi, W. A. 2014. Bottom-up regulation of capelin, a keystone forage species. PLoS ONE, 9: 1-12. https://doi.org/10.1371/ journal.pone.0087589

Buren, A. D., Murphy, H. M., Adamack, A. T., Davoren, G. K., Koen-Alonso, M., Montevecchi, W. A., Mowbray, F. K., Pepin P., Regular P. M., Robert D., Rose G. A., Stenson, G. B., and Varkey, D. 2019. The collapse and continued low productivity of a keystone forage fish species. Marine Ecology Progress Series, 616: 155-170. https://doi. org/10.3354/meps 12924

Carscadden, J. E., Frank, K. T., and Miller, D. S. 1989. Capelin (Mallotus villosus) spawning on the southeast shoal: influence of physical factors past and present. Canadian Journal of Fisheries and Aquatic Sciences, 46: 1743-1754. https://doi.org/10.1139/f89-221
Carscadden, J., and Vilhjalmsson, H. 2002. Capelin - What are they good for? Introduction. ICES Journal of Marine Science, 59: 863-869. https://doi.org/10.1006/ imsc.2002.1283

Chapman, A. R. 1981. Stability of sea urchin dominated barren grounds following destructive grazing of kelp in St. Margaret's Bay, Eastern Canada. Marine Biology, 62: 307-311. https://doi.org/10.1007/BF00397697

Chapman, A. R. O., and Johnson, C. R. 1990. Disturbance and organization of macroalgal assemblages in the Northwest Atlantic. Hydrobiologia, 192: 77-121. https://doi. org/10.1007/BF00006228

Crook, K. A., Maxner, E., and Davoren, G. K. 2017. Temperaturebased spawning habitat selection by capelin (Mallotus villosus) in Newfoundland. ICES Journal of Marine Science, 74: 1622-1629. https://doi.org/10.1093/icesjms/ $\underline{\text { fsx023 }}$

Davenport, J., Lonning, S., and Kjorsvik, E. 1986. Some mechanical and morphological properties of the chorions of marine teleost eggs. Journal of Fish Biology, 29: 289-301. https://doi.org/10.1111/j.1095-8649.1986.tb04946.x

Davoren, G. K. 2013. Divergent use of spawning habitat by male capelin (Mallotus villosus) in a warm and cold year. Behavioral Ecology, 24: 152-161. https://doi.org/10.1093/ beheco/ars 147

Davoren, G. K., May, C., Penton, P., Reinfort, B., Buren, A., Burke, C., Andrews, D., Montevecchi, W. A., Record, N., deYoung, B., Rose-Taylor, C., Bell, T., Anderson, J. T., Koen-Alonso, M., and Garthe, S. 2007. An ecosystembased research program for capelin (Mallotus villosus) in the northwest Atlantic: overview and results. Journal of Northwest Atlantic Fishery Science, 39, 35-48. https://doi. org/10.2960/J.v39.m595

Davoren, G. K., Anderson, J. T., and Montevecchi, W. A. 2006. Shoal behaviour and maturity relations of spawning capelin (Mallotus villosus) off Newfoundland: demersal spawning and diel vertical movement patterns. Canadian Journal of Fisheries and Aquatic Sciences, 63: 268-284. https://doi. org/10.1139/f05-204

DeBlois, E. M., and Leggett, W. C. 1993. Match/mismatch between the abundance of marine fish eggs and invertebrate predators: an analysis of Calliopius laeviusculus (Amphipoda: Gammaridae) population growth relative to the seasonal spawning cycle of capelin (Mallotus villosus). Canadian Journal of Fisheries and Aquatic Sciences, 50: 2581-2590. https://doi.org/10.1139/f93-282

Duggins, A. D. O., Simenstad, C. A., and Estes, J. A. 1989. Magnification of secondary production by kelp detritus in coastal marine ecosystems. Science, 245: 6-8.

Fahay, M. P. 2007. Early stages of fishes in the western North Atlantic Ocean Davis Strait, Southern Greenland and Flemish Cap to Cape Hatteras, Vol. 1. Nova Scotia, Canada: Northwest Atlantic Fisheries Organization.

Filbee-Dexter, K., and Scheibling, R. E. 2014. Sea urchin barrens as alternative stable states of collapsed kelp ecosystems. Marine Ecology Progress Series, 495: 1-25. https://doi. org $/ 10.3354 /$ meps 10573

Folke, C., Carpenter, S., Walker, B., Scheffer, M., Elmqvist, T., Gunderson, L., and Holling, C. S. 2004. Regime 
shifts, resilience, and biodiversity in ecosystem management. Annual Review of Ecology, Evolution, and Systematics, 35: 557-581. https://doi.org/10.1146/annurev. ecolsys.35.021103.105711

Frank, K. T., and Leggett, W. C. 1981. Prediction of egg development and mortality rates in capelin (Mallotus viliosus) from meteorological, hydrographic, and biological factors. Canadian Journal of Fisheries and Aquatic Sciences, 38: 1327-1338. https://doi.org/10.1139/f81-179

Gagnon, P., Himmelman, J. H., and Johnson, L. E. 2003. Algal colonization in urchin barrens: defense by association during recruitment of the brown alga Agarum cribrosum. Journal of Experimental Marine Biology and Ecology, 290: 179-196. https://doi.org/10.1016/S0022-0981(03)00077-7

Gagnon, P., St-Hilaire-Gravel, L. V., Himmelman, J. H., and Johnson, L. E. 2006. Organismal defenses versus environmentally mediated protection from herbivores: Unraveling the puzzling case of Desmarestia viridis (Phaeophyta). Journal of Experimental Marine Biology and Ecology, 334: 10-19. https://doi.org/10.1016/j. jembe.2006.01.012

Gagnon, P., Blain, C., and Vad, J. 2013. Living within constraints: Irreversible chemical build-up and seasonal temperaturemediated die-off in a highly acidic $\left(\mathrm{H}_{2} \mathrm{SO}_{4}\right)$ annual seaweed (Desmarestia viridis). Marine Biology, 160, 439-451. https://doi.org/10.1007/s00227-012-2101-8

Gaines, S. D., and Roughgarden, J. 1987. Fish in offshore kelp forests affect recruitment to intertidal barnacle populations. Science, 235: 479-481. https://doi.org/10.1126/ science.235.4787.479

Graham, M. H. 2004. Effects of local deforestation on the diversity and structure of Southern California giant kelp forest food webs. Ecosystems, 7: 341-357. https://doi. org/10.1007/s10021-003-0245-6

Konar, B. 2000. Seasonal inhibitory effects of marine plants on sea urchins: structuring communities the algal way. Oecologia, 125: 208-217. https://doi.org/10.1007/ $\underline{\mathrm{s} 004420000440}$

Lavigne, D. M. 1996. Ecological interactions between marine mammals, commercial fisheries and their prey: Unraveling the tangled web. In W. A. Montevecchi (Ed.), Studies of high-latitude seabirds. 4, Trophic relationships and energetics of endotherms in cold ocean systems (pp. 59-71). Canadian Wildlife Service Occasional Paper.

Lewis, K., Buren, A., Regular, P., Mowbray, F., and Murphy, H. 2019. Forecasting capelin Mallotus villosus biomass on the Newfoundland shelf. Marine Ecology Progress Series, 616: 171-183. https://doi.org/10.3354/meps 12930

Loder, J. W., Han, G., Galbraith, P. S., Chassé, J., and Van Der Baaren, A. 2013. Aspects of climate change in the Northwest Atlantic off Canada. Canadian Technical Report of Fisheries and Aquatic Sciences, 3045: x +190p.

Mikkelsen, N., and Pedersen, T. 2017. Invasive red king crabs feed on both spawned-out capelin and their eggs. Marine Ecology Progress Series, 563: 139-155. https://doi. org $/ 10.3354 /$ meps 11970

Molis, M., Wessels, H., Hagen, W., Karsten, U., and Wiencke, C. 2009. Do sulphuric acid and the brown alga Desmarestia viridis support community structure in Arctic kelp patches by altering grazing impact, distribution patterns, and behaviour of sea urchins? Polar Biology, 32: 71-82. https:// doi.org/10.1007/s00300-008-0504-2

Mullowney, D., Maillet, G., Dawe, E., Rose, G., and Rowe, S. 2016. Spawning delays of northern capelin (Mallotus villosus) and recovery dynamics: A mismatch with ice-mediated spring bloom? Progress in Oceanography, 141: 144-152. https:// doi.org/10.1016/j.pocean.2015.12.006

Murphy, H. M., Pepin, P., and Robert, D. 2018. Re-visiting the drivers of capelin recruitment in Newfoundland since 1991. Fisheries Research, 200: 1-10. https://doi.org/10.1016/j. fishres.2017.12.005

Nakashima, B. S., and Wheeler, J. P. 2002. Capelin (Mallotus villosus) spawning behaviour in Newfoundland waters - the interaction between beach and demersal spawning. ICES Journal of Marine Science, 59: 909-916. https://doi. org/10.1006/jmsc.2002.1261

Penton, P. M., Davoren, G. K., Montevecchi, W. A., and Andrews, D. 2012. Beach and demersal spawning in capelin (Mallotus villosus) on the northeast Newfoundland coast: egg developmental rates and mortality. Canadian Journal of Zoology, 90: 248-256. https://doi.org/10.1139/z11-132

Penton, P. M., and Davoren, G. K. 2012. Physical characteristics of persistent deep-water spawning sites of capelin: Importance for delimiting critical marine habitats. Marine Biology Research, 8: 778-783. https://doi.org/10.1080/17 $\underline{451000.2012 .678858}$

2013. A common garden experiment on capelin (Mallotus villosus) early life history stages to examine use of beach and deep-water spawning habitats. Journal of Experimental Marine Biology and Ecology, 439: 54-60. https://doi. org/10.1016/j.jembe.2012.10.009

Shadrin, A. M., Makhotin, V. V., and Eriksen, E. 2020. Incubation temperature effect on qualitative and quantitative composition of abnormalities and mortality rate in embryogenesis of the Barents Sea capelin Mallotus villosus (Osmeridae). Journal of Ichthyology, 60: 79-89. https://doi. org/10.1134/S0032945220010142

Sjare, B., Nakashima, B., Mercer, D., Mercer D, and Mercer, D. 2003. Integrating scientific and local ecological knowledge to identify potential critical habitats: A case study in Placentia Bay, Newfoundland. Canadian Science Advisory Secretariat, Department of Fisheries and Ocean \#2003/114.

Stewart, N. L., and Konar, B. 2012. Kelp forests versus urchin barrens: alternate stable states and their effect on sea otter prey quality in the Aleutian Islands. Journal of Marine Biology, 2012: 1-12. https://doi.org/10.1155/2012/492308

Templeman, W. 1948. The life history of the caplin (Mallotus villous O. F. Müller) in Newfoundland waters. Bulletin of the Newfoundland Government Laboratory, 17: 1-151.

van Oppen, M. J. H., Olsen, J. L., Stam, W. T., van den Hoek, C., and Wiencke, C. 1993. Arctic-Antarctic disjunctions in the benthic seaweeds Acrosiphonia arcta (Chlorophyta) and Desmarestia viridis/willii (Phaeophyta) are of recent origin. Marine Biology, 115: 381-386. https://doi.org/10.1007/ BF00349835

Wentworth, C. K. 1922. A scale of grade and class terms for clastic sediments. The Journal of Geology, 30: 377-392. https://doi.org/10.1086/622910 
